\title{
DESIGN AND DYNAMIC ANALYSIS OF A NEW RAIL GRINDING DEVICE USING CLOSED ABRASIVE BELT
}

\author{
Fan, W. G. ${ }^{* * *}$; Hou, G. Y. ; Wang, W. X. ${ }^{*}$; Z Zhang, X. L. ${ }^{*} \&$ Wang, J. D. \\ ${ }^{*}$ School of Mechanical, Electronic and Control Engineering, Beijing Jiaotong University, \\ Beijing 100044, P. R. China \\ ** Key Laboratory of Vehicle Advanced Manufacturing, Measuring and Control Technology, \\ Ministry of Education, Beijing 100044, P. R. China \\ E-Mail:wgfan@bjtu.edu.cn,17121243@bjtu.edu.cn,14116345@bjtu.edu.cn,18121265@bjtu.edu.cn, \\ 18121260@bjtu.edu.cn (" Corresponding author)
}

\begin{abstract}
With the rapid development of modern abrasive belt grinding, a novel rail grinding method based on closed-structured belt grinding technology has been proposed in this paper. Correspondingly, a new rail grinding device with the closed abrasive belt was designed according to engineering requirements and constraints. It is equipped with four built-in grinding units aiming to achieve required material removal through lateral, vertical, and rotational movements. Afterward, a corresponding dynamic simulation model for the designed device was established in SIMPACK software to verify its working performance in terms of the four dynamic indices, including lateral vibration acceleration, vertical vibration acceleration, axle transverse force as well as derailment coefficient. The results of those indices both for the linear and curved tracks are within the limits, which have proved the design rationality of the new rail grinding device.

(Received, processed and accepted by the Chinese Representative Office.)
\end{abstract}

Key Words: Rail Grinding, Abrasive Belt, Device Design, Dynamic Analysis

\section{INTRODUCTION}

Due to the harsh service environment mainly brought by the complex vehicle-track interaction, the rail surface and its inner part are prone to suffer from various defects such as corrugation, crack, spalling, and squat [1,2]. Currently, rail grinding has been globally employed as a mainstream and routine maintenance means to remove those flaws, and finally to prolong the rail's serving life as well as to strengthen the train's running stability $[3,4]$.

The most popular rail grinding technology at present is the facing grinding by the abrasive wheel $[5,6]$. Fig. 1 shows the fundamental principle of a typical grinding train that applies this processing method. The grinding train is totally equipped with 96 grinding wheels, which are set with different tilt angles and process parameters on each side (such as the grinding pressure and the rotation speed). They are orderly placed according to different grinding positions on rail profile to realize metal removal. After years of theoretical research and practical application, material removal mechanism, grinding process and equipment development have been extensively explored [7-11]. Besides, there are also some other rail grinding methods, including the peripheral grinding by abrasive wheel $[12,13]$, the milling by combined cutter blades [14], and the high-speed grinding by non-driven abrasive wheel [15]. They all have obtained much success in their own specific fields and have reflected different development tendencies of the rail grinding technology towards intellectualization, high efficiency, high quality, diversification, and greenization.

Recently, in our previous study [16-18], a novel rail grinding technology introducing closed-structured belt grinding for direct rail maintenance has been proposed and experimentally investigated, having revealed the convincing potential advantages in metal removal rate, dust collection, surface quality, etc. 


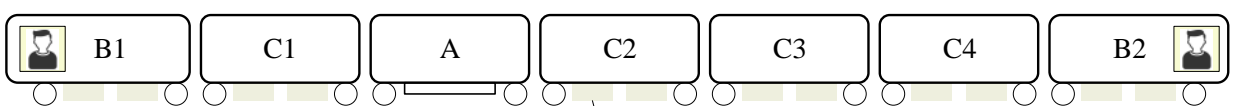

Grinding device

Abrasive wheel basket

Abrasive wheel

Figure 1: Schematic diagram of GMC96.

Figs. $2 \mathrm{a}$ and $2 \mathrm{~b}$ separately present the overall structure of a single grinding head and joint operation model of multiple grinding heads of the mentioned novel rail grinding technology. As shown, the contact wheel consists of a rigid hub wrapped by an elastic rubber layer. Applied force drives abrasive belt contact with the rail surface, which then induces a material removal process. In the practical grinding process, it usually distributes contact wheels along the cross-section curved of the railhead, so that a continuous material removal contour can be formed.

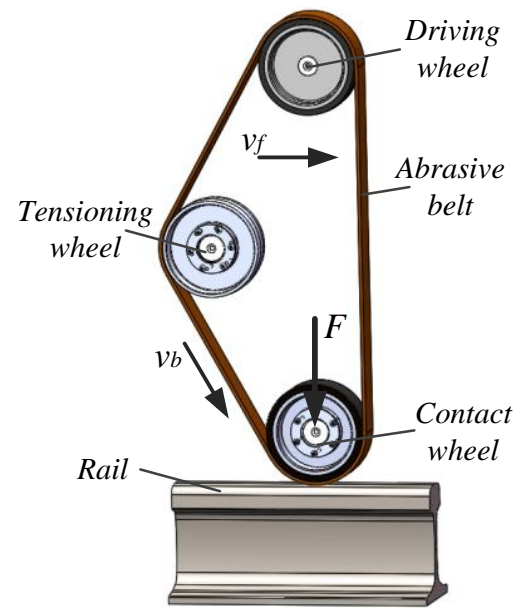

a)

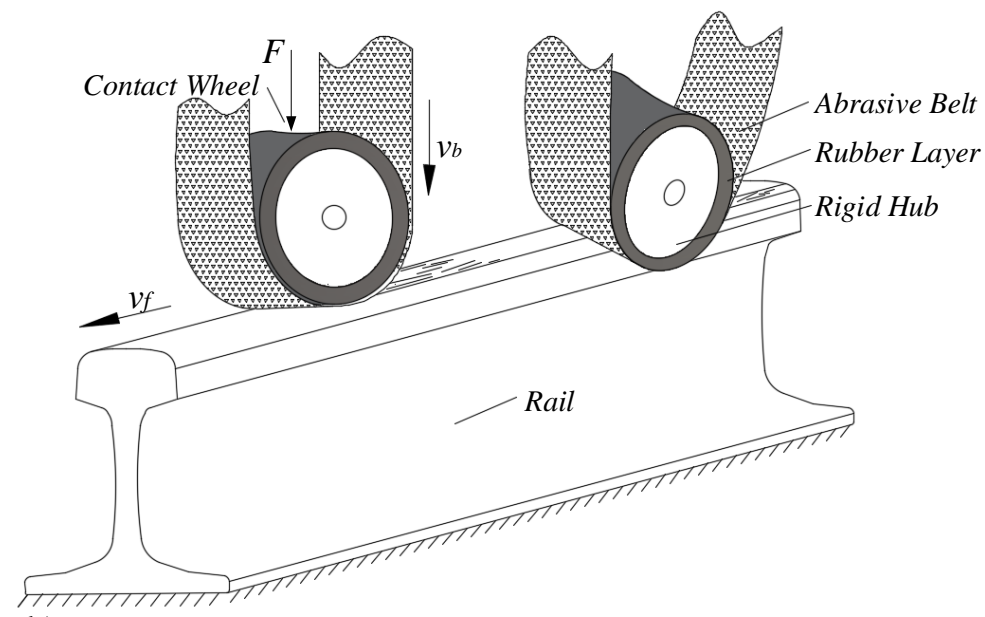

b)

Figure 2: Working principle of rail grinding using abrasive belt: a) overall structure of a single grinding head, b) joint operation of multiple grinding heads.

This paper is to promote the engineering application of the abrasive belt grinding technology. For that, a new rail grinding device based on belt grinding with a closed abrasive belt is developed initially according to engineering requirements and rail grinding constraints. Then, the multi-body dynamic simulations both for straight line and curved track are conducted to investigate and evaluate the dynamic performance of the aforementioned rail grinding device.

\section{DESIGN OF THE RAIL GRINDING DEVICE}

\subsection{Analysis on the engineering requirements and constraints}

The optimal rail profile and wheel tread of the vehicle provide the optimal properties for the good wheel-rail contact condition [19], including the resistance to wear, fatigue and corrugation development, the minimization of noise, the maximization of stability and safety, etc. Namely, restoring the rail profile has become one of the most important priorities in rail 
grinding applications. Fig. 3 gives a representative rail profile labelled as $60 \mathrm{~N}$ for China High-Speed Railway (CHSR), which is composed of seven segment arcs with four kinds of radii of curvature. Every angle to guide the rail grinding pattern planning is defined as the angle between the tangential direction on the contact point of the rail profile curved and the spatial horizontal direction.

In the actual grinding operation, the rail profile is generally produced under the combined action of many grinding units with different grinding angles and processing parameters [20]. To reduce the number of the required grinding units and increase the efficiency of rail grinding with the abrasive belt, the rubber contact wheel with the concave peripheral surface is used to realize the arc enveloping curve other than the linear enveloping curve. Supposing that the radius of curvature for the concave peripheral surface of the rubber contact wheel equals $300 \mathrm{~mm}$, according to the precision of the rail profile $\pm 0.2 \mathrm{~mm}$ required in the acceptance specification of rail grinding for CHSR, only six times of enveloping allows the angle range from $-20^{\circ}$ to $+70^{\circ}$, as shown in Fig. 4 .

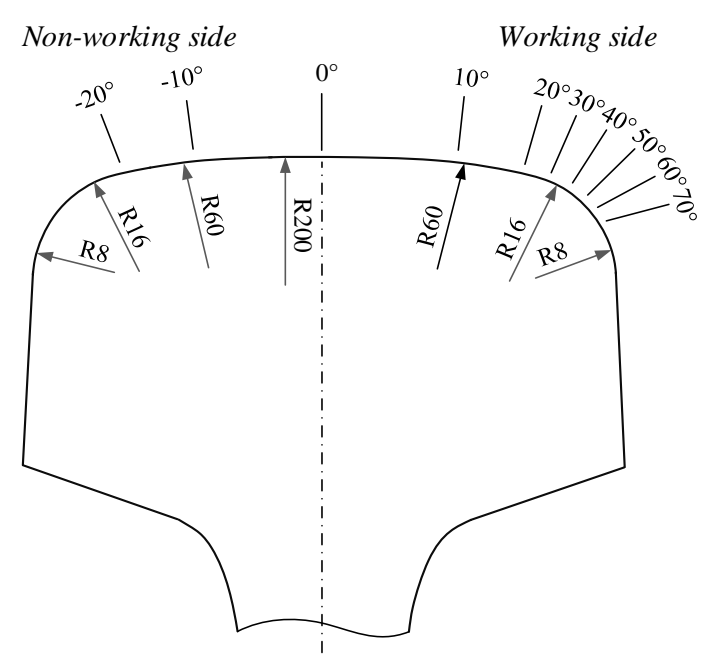

Figure 3: Rail profile 60N.

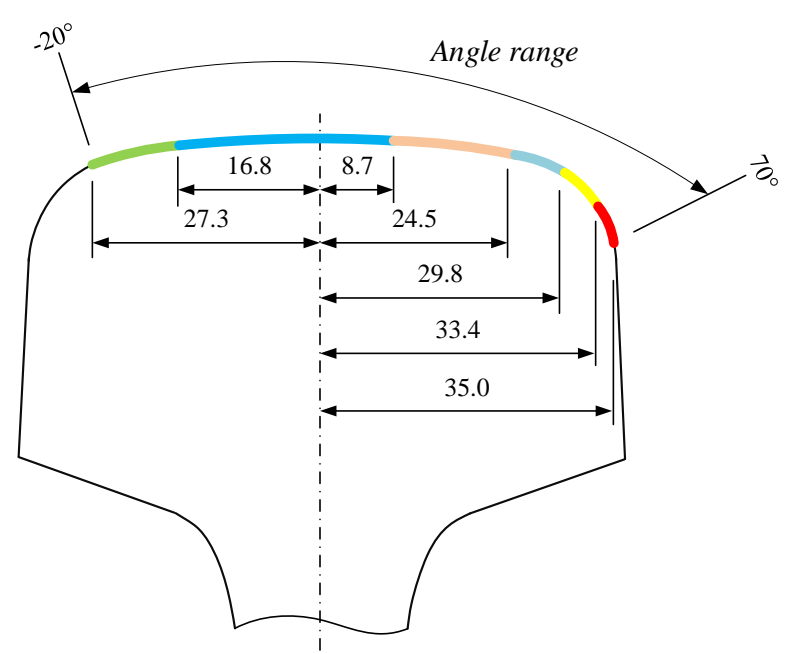

Figure 4: Enveloping diagram of rail profile $60 \mathrm{~N}$.

Another factor of rail grinding is the corrugation, which refers to the periodical irregularities with certain wavelength and frequency along the longitudinal direction of the rail and has a great impact on the stability, noise, and service life of both the rail and vehicle wheel. From the point of rail grinding, the corrugation can be only slowed down. Based on the traditional planer process, the contact component composed of three fixed contact wheels is designed so as to form a longitudinal processing area with a length of $400 \mathrm{~mm}$, which meets the corrugation requirement in the new high-speed and existing railways of China.

According to the analysis of the rail shape of the high-speed rail and the analysis of the rail-wave grinding, it is determined that the grinding car uses the concave contact wheel to divide the rail into six sections and fully envelop the rail. On the basis of the Assembly Technical Conditions of Rail Grinding Device formulated by China Railway Corporation [21], the dimension limitation of the rail grinding device is propositionally given as follows: length $\leq 3820 \mathrm{~mm}$, width $\leq 2512 \mathrm{~mm}$ and height $\leq 1150 \mathrm{~mm}$. Combined with the structural analysis of the existing grinding car, a three-dimensional model of the rail belt grinding device is established.

\subsection{Design and mechanical modelling of the rail grinding device}

As the key core of the designed rail grinding device, the individual grinding unit is composed of the fixed base board, the abrasive belt, the driving/tensioning wheel, the idle wheel, the contact component made up of three rubber contact wheels, the hydraulic motor, the 
tensioning cylinder, the guide pillar for tensioning, and the guide pillar for the vertical movement, as shown in Fig. 5. In view of the aforementioned analysis on the grinding angle range, the hydraulic motor is ideally chosen according to the spatial constraints of the grinding unit because of its advantages of compact size, small inertia, low noise and long service life. Then, the relative locations of the designed contact component and the abrasive belt can be adjusted in the horizontal direction to make full use of the grinding performance of the abrasive grains on the surface of the abrasive belt.

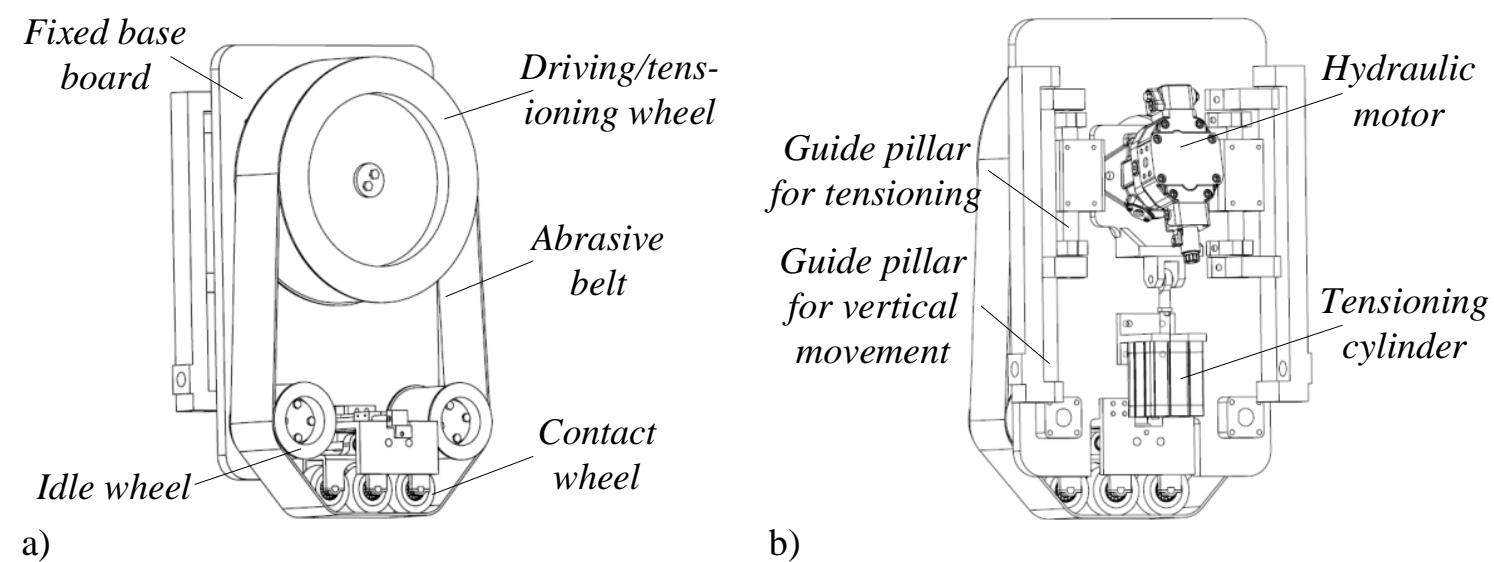

Figure 5: Mechanical model of the grinding unit: a) front view, b) back view.

The final mechanical model of the rail grinding device with the closed abrasive belt is shown in Fig. 6 and its main design parameters are listed in Table I. Four individual grinding units are integrated into one rail grinding device. Moreover, the designed rail grinding device generally has two statuses: the hanging mode without grinding and the working mode with grinding. The rail grinding device will not be released to contact the rail surface until the grinding process command is issued from the control system. Once the grinding process is completed or the grinding train is passing the switch or other restricted areas, the rail grinding device will be mostly lifted by the hydraulic device with the locking function. In the designed device, the four built-in grinding units can be propelled to invade the rail surface and remove the required material under constant pressure through lateral, vertical, and rotational movements. Then the dynamic simulation model is established in SIMPACK software to verify its working performance in terms of the four dynamic indices of the lateral vibration acceleration, the vertical vibration acceleration, and the axle transverse force as well as the derailment coefficient for the straight line track and curved track.

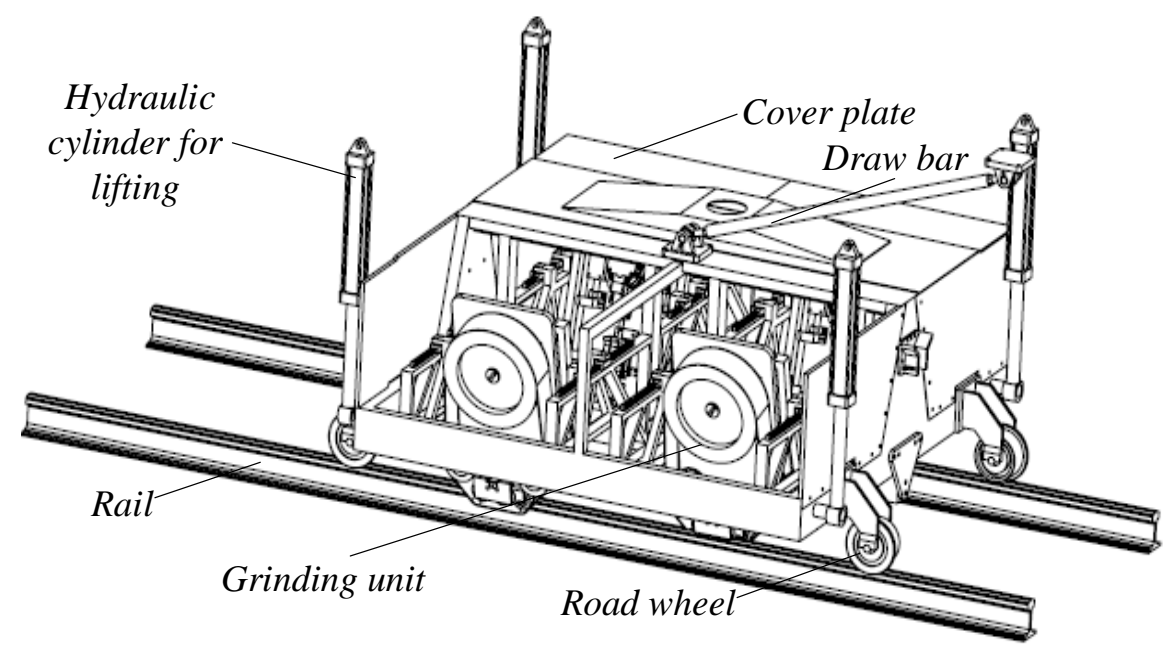

Figure 6: Mechanical model of the rail grinding device. 
Table I: Main design parameters of the rail grinding device.

\begin{tabular}{|c|l|c|}
\hline No & \multicolumn{1}{|c|}{ Parameters } & Values \\
\hline 1 & $\begin{array}{l}\text { Dimensions of the grinding device }(\mathrm{mm}): \\
\text { length } \times \text { width } \times \text { height }\end{array}$ & $3160 \times 2500 \times 1040$ \\
\hline 2 & Mass of the grinding device $(\mathrm{t})$ & 2.43 \\
\hline 3 & Number of the grinding units & 4 \\
\hline 4 & Working speed for the grinding device $(\mathrm{km} / \mathrm{h})$ & $12-32$ \\
\hline 5 & Rotate speed of the abrasive belt $(\mathrm{m} / \mathrm{s})$ & $30-40$ \\
\hline 6 & Width of the abrasive belt $(\mathrm{mm})$ & 100 \\
\hline
\end{tabular}

\section{DYNAMIC SIMULATION OF THE RAIL GRINDING DEVICE}

\subsection{Dynamic simulation modelling in SIMPACK}

Simulation method is an important means to resolve kinds of engineering problems [22]. Due to the limitations of experimental conditions in the railway locomotive industry, the dynamic simulation method is adopted to test and verify the performance of the designed vehicle equipment. A core factor to be considered is the rail irregularity excitation, which is unavoidable and has a great influence on stability, safety and component life of the vehicle equipment. The widely accepted description of the rail irregularity excitation is called the track spectrum. In order to guarantee the reliability of the study as much as possible, the fifthgrade track spectrum of U.S. railways is introduced into the subsequent dynamic simulation model.

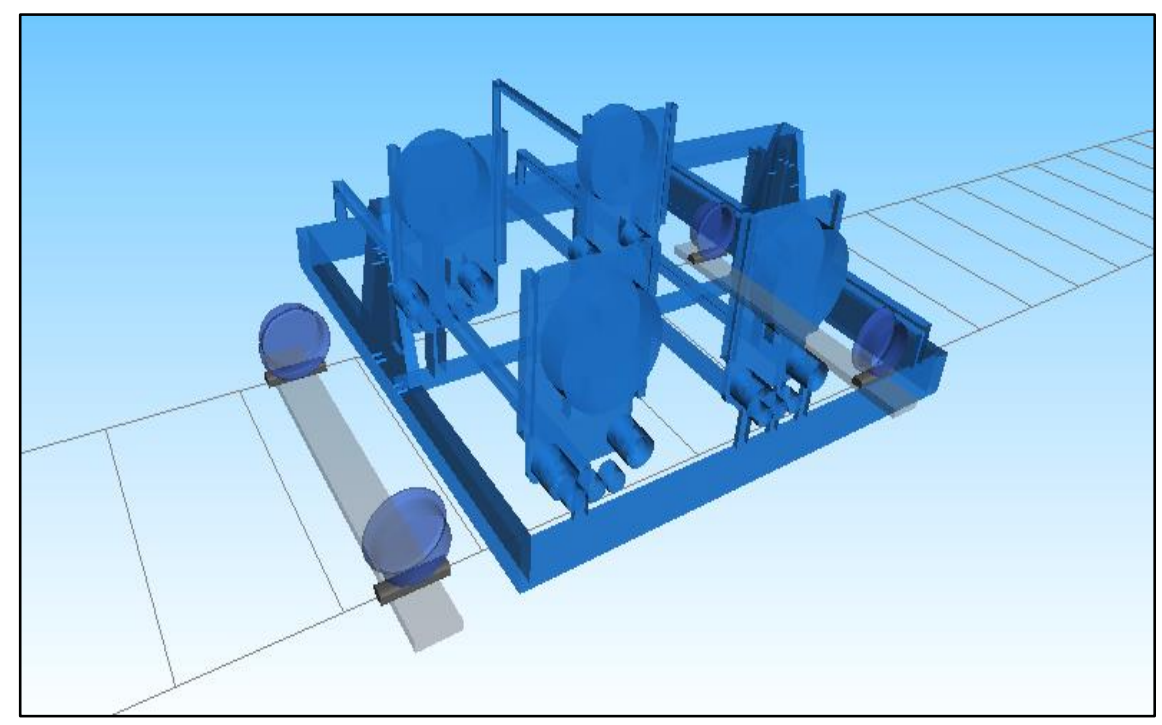

Figure 7: Dynamic simulation model of the designed rail grinding device.

Fig. 7 shows the dynamic simulation model of the rail grinding device with the closed abrasive belt established in the SIMPACK software and the basic components and parts including the road wheel, the framework, and the grinding unit with the closed abrasive belt are considered. The framework with six degrees of freedom is connected to the axle through the suspension force. Moreover, the wheel-rail contact geometric relationship, the wheel-rail force and the axle suspension are set as the non-linear elements. The main parameters in the SIMPACK dynamic simulation are listed in Table II. 
Table II: Main parameters of Simpack dynamic simulation.

\begin{tabular}{|c|l|c|}
\hline No & \multicolumn{1}{|c|}{ Parameters } & Values \\
\hline 1 & Moment of inertia of the grinding car x/y/z $\left(\mathrm{t} \cdot \mathrm{m}^{2}\right)$ & $13.2 / 56 / 53.5$ \\
\hline 2 & Position of the centre of the mass $\mathrm{x} / \mathrm{y} / \mathrm{z}(\mathrm{mm})$ & $1390 / 0 / 250$ \\
\hline 3 & Mass of each road wheel $(\mathrm{kg})$ & 53.2 \\
\hline 4 & Moment of inertia of the grinding car x/y/z $\left(\mathrm{kg} \cdot \mathrm{m}^{2}\right)$ & $0.37 / 0.76 / 0.37$ \\
\hline 5 & Diameter of each road wheel $(\mathrm{mm})$ & 350 \\
\hline 6 & Length of the draw bar $(\mathrm{mm})$ & 1600 \\
\hline 7 & Stiffness of the draw bar $(\mathrm{kN} / \mathrm{m})$ & 2000 \\
\hline 8 & Damping of the draw bar $(\mathrm{kN} \cdot \mathrm{s} / \mathrm{m})$ & 3 \\
\hline 9 & DOF of the joints at each $\mathrm{road}$ wheel & $\gamma$ \\
\hline 10 & DOFs of the joints at each side of the draw bar & $\gamma, \psi$ \\
\hline 11 & DOF of the contact wheels & $z, y, z, \varphi, \gamma, \psi$ \\
\hline 12 & DOFs of the grinding device & $60 \mathrm{~N}$ \\
\hline 13 & Rail profile & \\
\hline
\end{tabular}

\subsection{Assessment criteria of dynamic simulation}

The assessment is carried out according to the China National Standard (CNS): Dynamic Performance Evaluation and Test Method for Particular Class Vehicles and Tracked Machine [23]. Therefore, for the purpose of improving the stability of the rail grinding device, the lateral and vertical vibration accelerations should be fully considered and their maximum allowable values are respectively $4.91 \mathrm{~m} / \mathrm{s}^{2}$ and $6.87 \mathrm{~m} / \mathrm{s}^{2}$. If the number of lateral and vertical vibration accelerations exceeding the limit in $100 \mathrm{~km}$ railway is no more than three, the assessment would be thought to be qualified. The indices of the derailment coefficient and the axle transverse force are used to evaluate the stability and safety of the rail grinding device. The first limit of the derailment coefficient (eligibility criteria) is no more than 1.2 and the second limit of the derailment coefficient (safety margin criteria) is no more than 1.0. With the wheel static load, according to the equation in the above CNS, the axle transverse force can be calculated as $33.41 \mathrm{kN}$.

\section{DISCUSSIONS OF DYNAMIC SIMULATION RESULTS}

According to the rail grinding principle, during the rail grinding operation, different grinding units with the closed abrasive belt are propelled to realize different attitudes and positions corresponding to the required grinding angles of the rail profile, thus leading to different dynamic characteristics of the rail grinding device. Asymmetric grinding means that the deflection angles of the grinding units on both sides of the grinding device are different, thus certainly weakening the dynamic performance of the rail grinding device. Therefore, the dynamic simulations of the asymmetric grinding are respectively carried out under the straight line and curved track conditions.

\subsection{Straight line grinding condition}

The working speed of the designed rail grinding device in the SIMPACK simulation ranges from 12 to $32 \mathrm{~km} / \mathrm{h}$ and the grinding angle of the rail profile ranges from $-20^{\circ}$ to $60^{\circ}$, where $10^{\circ}$ is determined as the angular spacing of the grinding units on both sides of the grinding device. The angles of common rail top grinding for the straight line condition are $0^{\circ}$ to $+10^{\circ}$, $0^{\circ}$ to $+20^{\circ},-10^{\circ}$ to $+20^{\circ},-10^{\circ}$ to $0^{\circ},-10^{\circ}$ to $+10^{\circ},-20^{\circ}$ to $0^{\circ},-20^{\circ}$ to $-10^{\circ},-20^{\circ}$ to $+10^{\circ},-20^{\circ}$ to $+20^{\circ}$. Then the dynamic indices of the lateral vibration acceleration, the vertical vibration 
acceleration, the axle transverse force and the derailment coefficient can be calculated. Fig. 8 shows the dynamic simulation results for the common rail top grinding with the grinding angle range from $-20^{\circ}$ to $20^{\circ}$. It is clear that the lateral vibration acceleration, the vertical vibration acceleration, the axle transverse force and the derailment coefficient display an upward trend with the increase in the working speed of the rail grinding device. Among the 4 indices, the lateral vibration acceleration is the least affected by the asymmetrical angle, whereas the derailment coefficient is the most affected by the asymmetrical angle. However, all the four indices are fully consistent with the dynamic requirements for rail vehicles without exception.

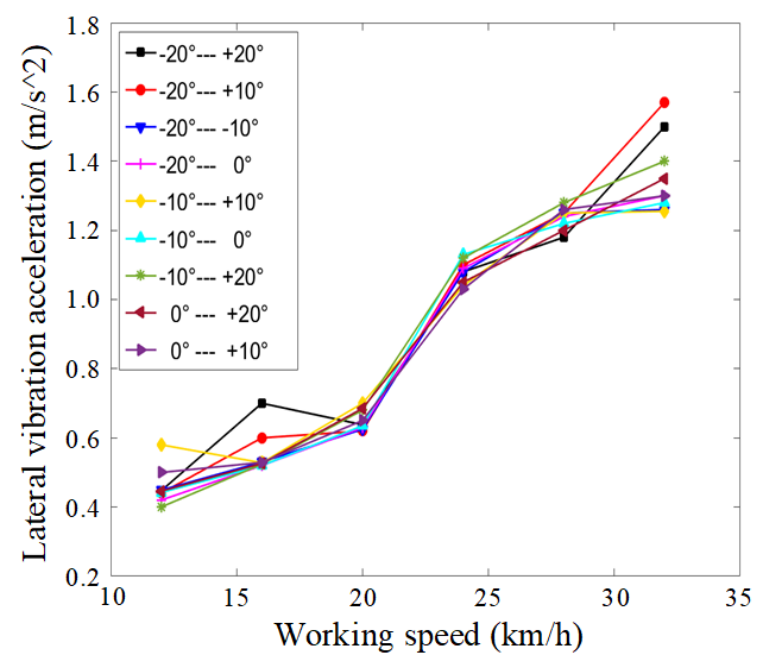

a)

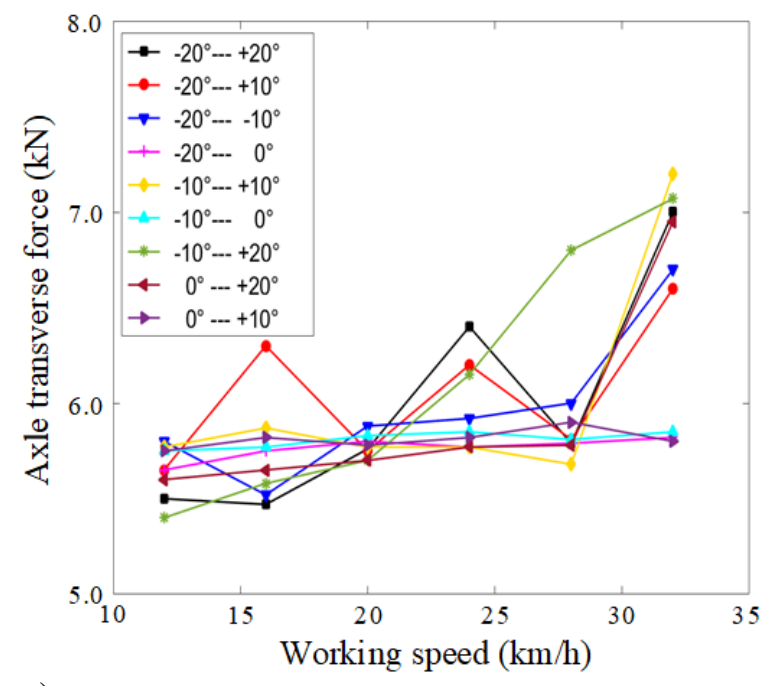

c)

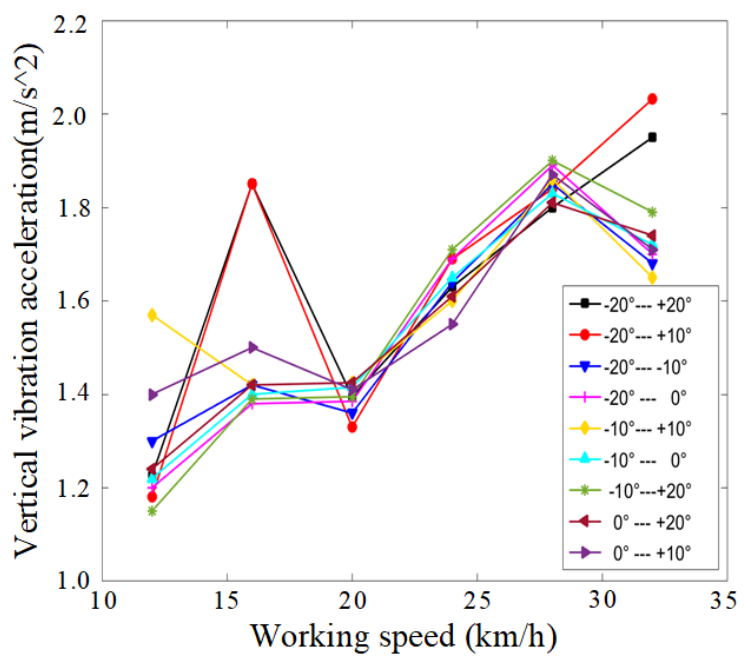

b)

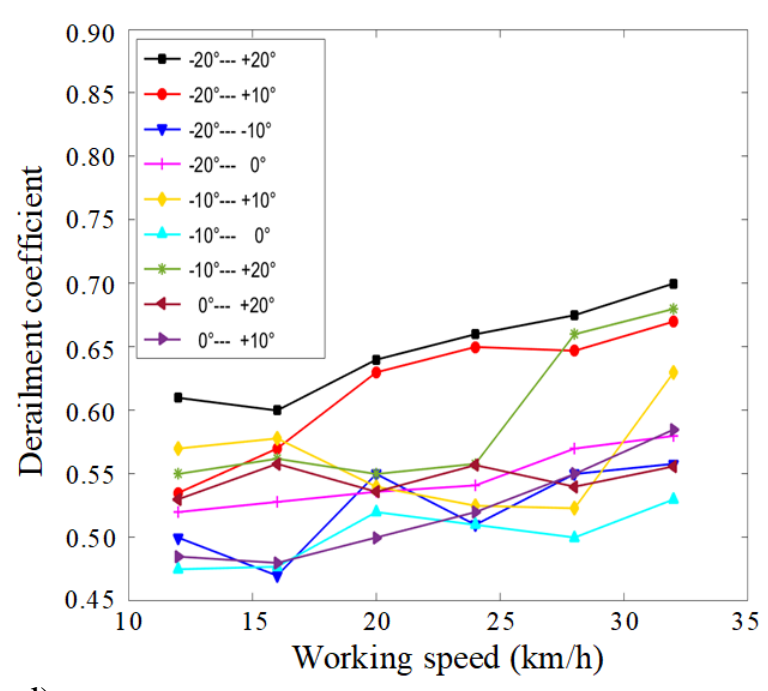

d)

Figure 8: Dynamic simulation results of the rail top grinding for the straight line.

Fig. 9 shows the dynamic simulation results of the whole rail profile grinding with the grinding angle range from $-20^{\circ}$ to $60^{\circ}$. The angles of the whole rail profile grinding for the straight line condition are $0^{\circ}$ to $+30^{\circ}, 0^{\circ}$ to $+40^{\circ}, 0^{\circ}$ to $+50^{\circ}, 0^{\circ}$ to $+60^{\circ},-10^{\circ}$ to $+30^{\circ},-10^{\circ}$ to $+40^{\circ},-10^{\circ}$ to $+50^{\circ},-10^{\circ}$ to $+60^{\circ},-20^{\circ}$ to $+30^{\circ},-20^{\circ}$ to $+40^{\circ},-20^{\circ}$ to $+50^{\circ},-20^{\circ}$ to $+60^{\circ}$. The lateral vibration acceleration and the vertical vibration acceleration also display the almost linear growth trends. The axle transverse force is changed slowly in the initial stage and then increases fast. The variation trend is contrary to the tendency of the derailment coefficient. It should be pointed out that the maximum value of the derailment coefficient reaches 0.98 under the working speed of the rail grinding $(32 \mathrm{~km} / \mathrm{h})$ and the maximum grinding angle 
difference $\left(-20^{\circ}\right.$ versus $\left.60^{\circ}\right)$ of the grinding units. However, the maximum value of the derailment coefficient (0.98) is still considered to be qualified, because the maximum value is less than the second limit (1.0) of the derailment coefficient (safety margin criteria). More importantly, the actual working speed of the rail grinding device is generally no higher than $20 \mathrm{~km} / \mathrm{h}$.

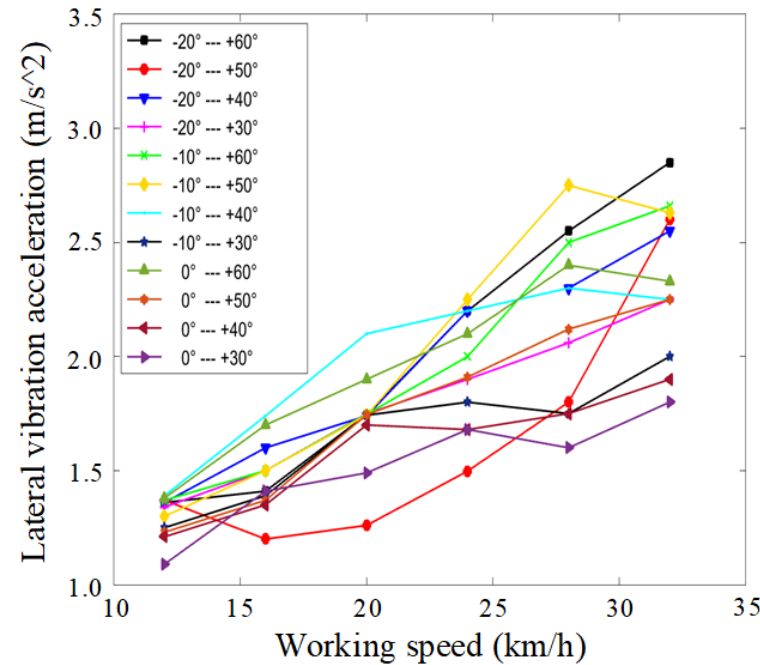

a)

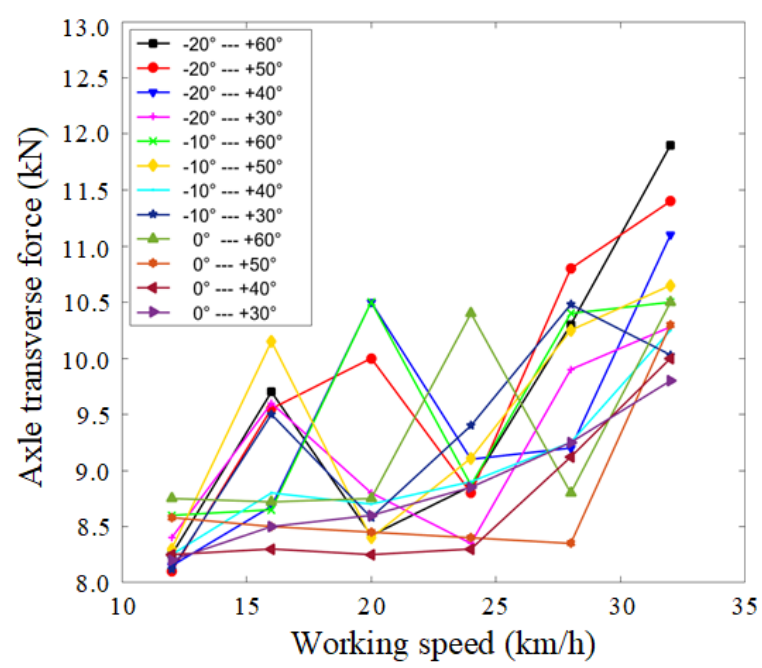

c)

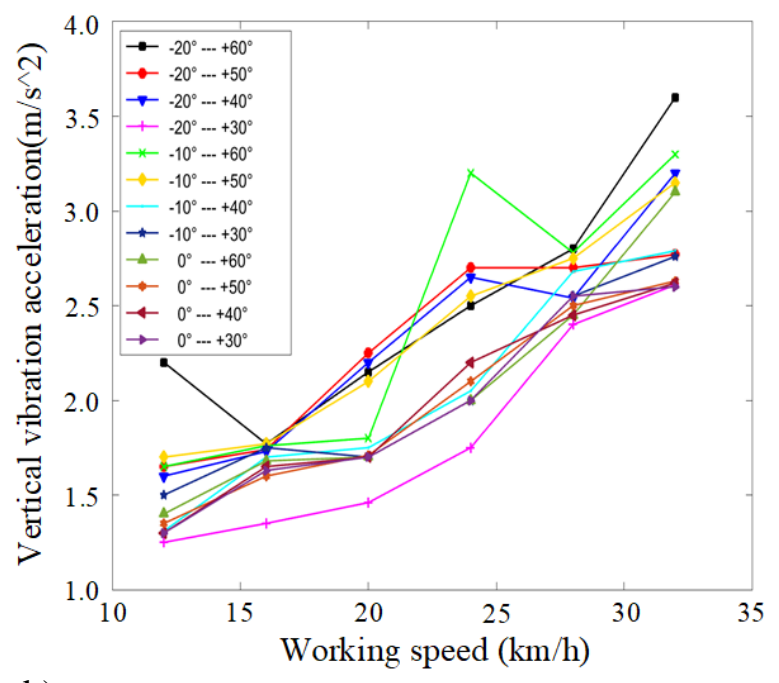

b)

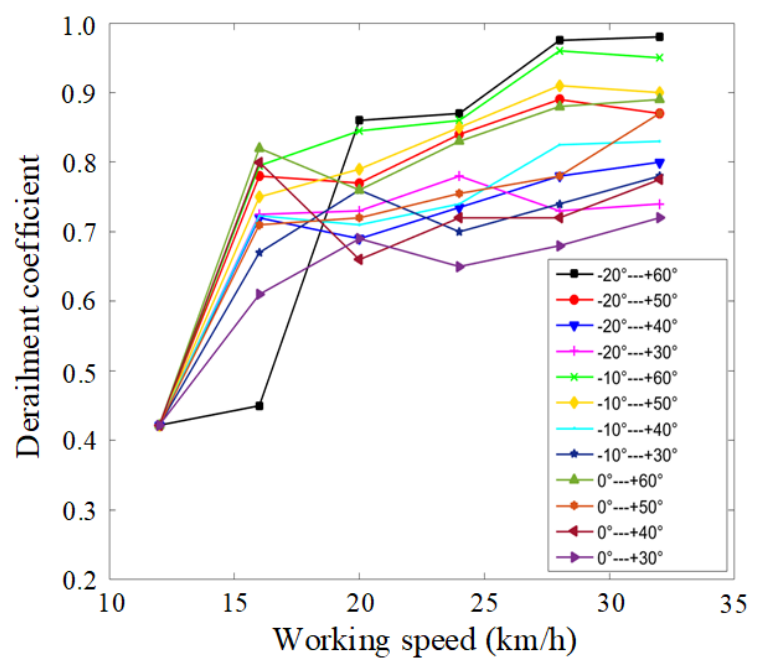

d)

Figure 9: Dynamic simulation results of the whole rail profile grinding for the straight line.

\subsection{Curved grinding condition}

The curved railway "line-easement curve-circular curve-easement curve-line" is added into the dynamic simulation model. Fig. 10 shows the dynamic simulation results for the rail top grinding with the grinding angle range from $-20^{\circ}$ to $20^{\circ}$. The angles of common rail top grinding for the curved condition are $-20^{\circ}$ to $+20^{\circ},-20^{\circ}$ to $+10^{\circ},-20^{\circ}$ to $-10^{\circ},-20^{\circ}$ to $0^{\circ},-10^{\circ}$ to $0^{\circ}, 0^{\circ}$ to $+10^{\circ}, 0^{\circ}$ to $+20^{\circ},-10^{\circ}$ to $+20^{\circ},-10^{\circ}$ to $+10^{\circ}$. It can be seen that the four dynamic indices are fully consistent with the requirement for rail vehicles. With the increase in the radius of curvature, both the lateral vibration acceleration and the vertical vibration acceleration show a growth trend. The lateral vibration acceleration is more sensitive to the grinding angle difference and the curves shown in Fig. 10 a are relatively dispersed. In contrast, the axle transverse force and the derailment coefficient show a downward trend with 
the increase in the radius of curvature. The maximum axle transverse force $(9.436 \mathrm{kN})$ and the maximum derailment coefficient (0.705) are determined to be qualified.

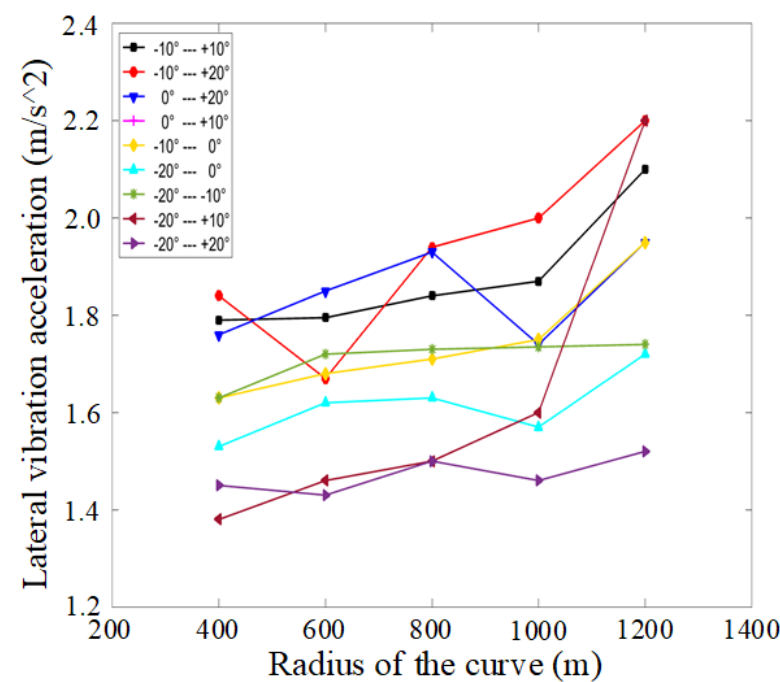

a)

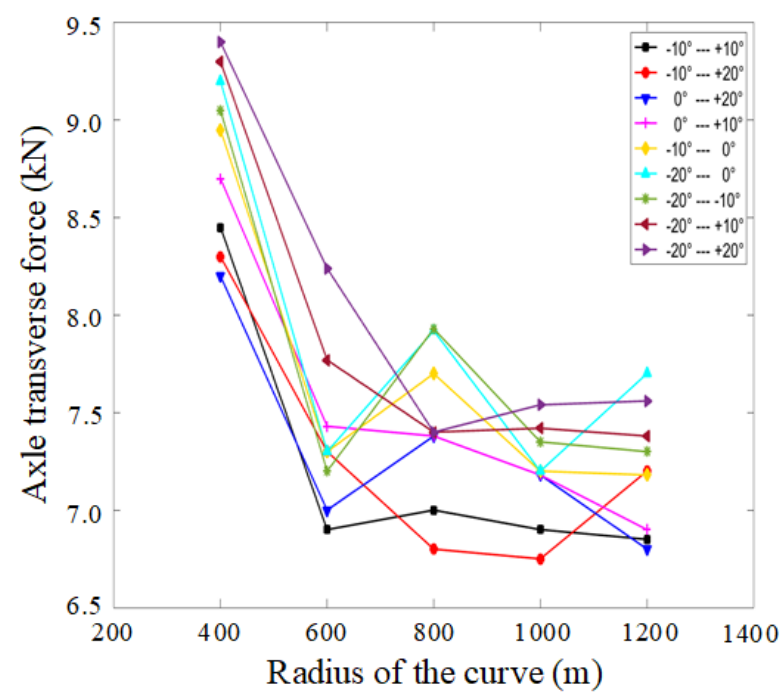

c)

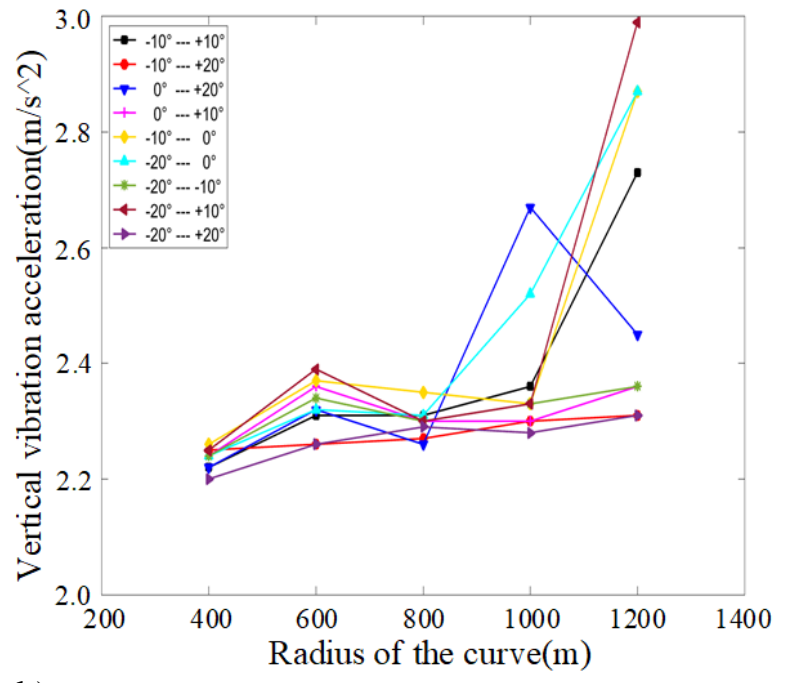

b)

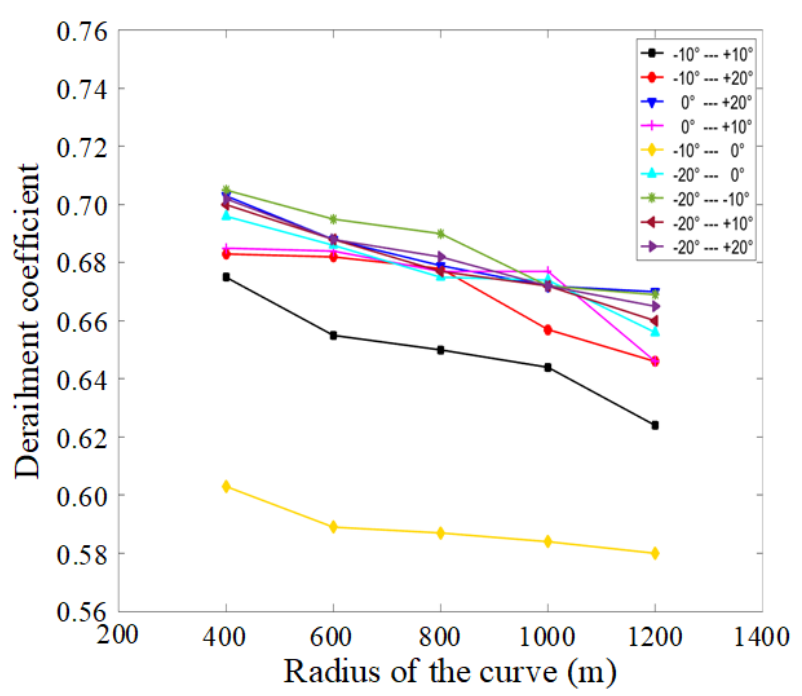

d)

Figure 10: Dynamic simulation results of the rail top grinding for the curved track.

Fig. 11 shows the dynamic simulation results for the whole rail profile grinding with the grinding angle range from $-20^{\circ}$ to $60^{\circ}$. The angles of the whole rail profile grinding for the curved condition are $0^{\circ}$ to $+30^{\circ}, 0^{\circ}$ to $+40^{\circ}, 0^{\circ}$ to $+50^{\circ}, 0^{\circ}$ to $+60^{\circ},-10^{\circ}$ to $+30^{\circ},-10^{\circ}$ to $+40^{\circ}$, $-10^{\circ}$ to $+50^{\circ},-10^{\circ}$ to $+60^{\circ},-20^{\circ}$ to $+30^{\circ},-20^{\circ}$ to $+40^{\circ},-20^{\circ}$ to $+50^{\circ},-20^{\circ}$ to $+60^{\circ}$. The variation tendencies of the lateral vibration acceleration, the vertical vibration acceleration, the axle transverse force and the derailment coefficients are consistent with that of the rail top grinding with the grinding angle range from $-20^{\circ}$ to $20^{\circ}$. However, their maximum values are larger, because the larger angle difference among the grinding units allows the more asymmetrical quality distribution of the grinding device. As shown in Fig. $11 \mathrm{~d}$, the maximum derailment coefficient value (1.009) is beyond the second limit (1.0) of the derailment coefficient (safety margin criteria) for the radius of curvature of $400 \mathrm{~m}$. However, the dynamic performance of the designed rail grinding device for the curved railway is still thought to be qualified now because the minimum radius of curvature is no less than $800 \mathrm{~m}$ for China's High-Speed Rail. 


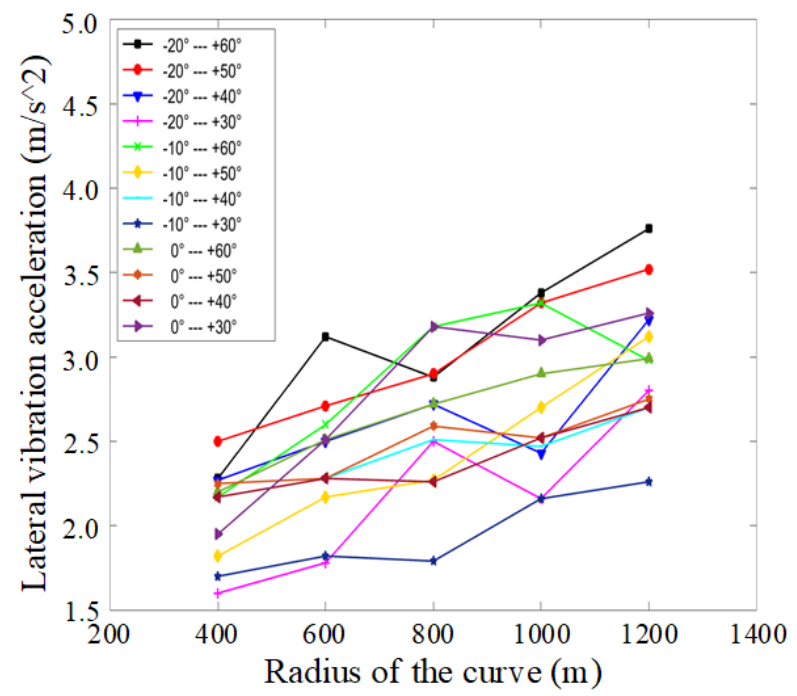

a)

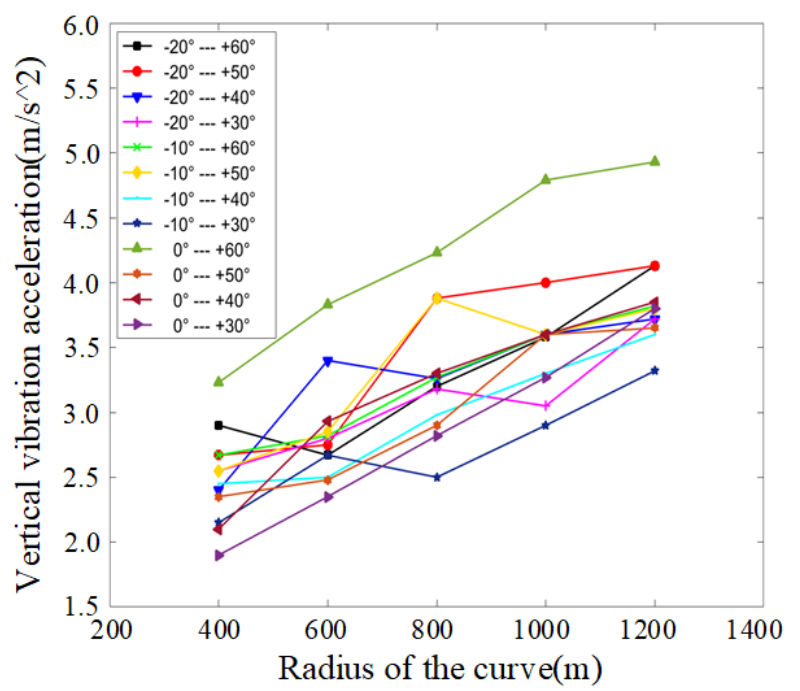

b)
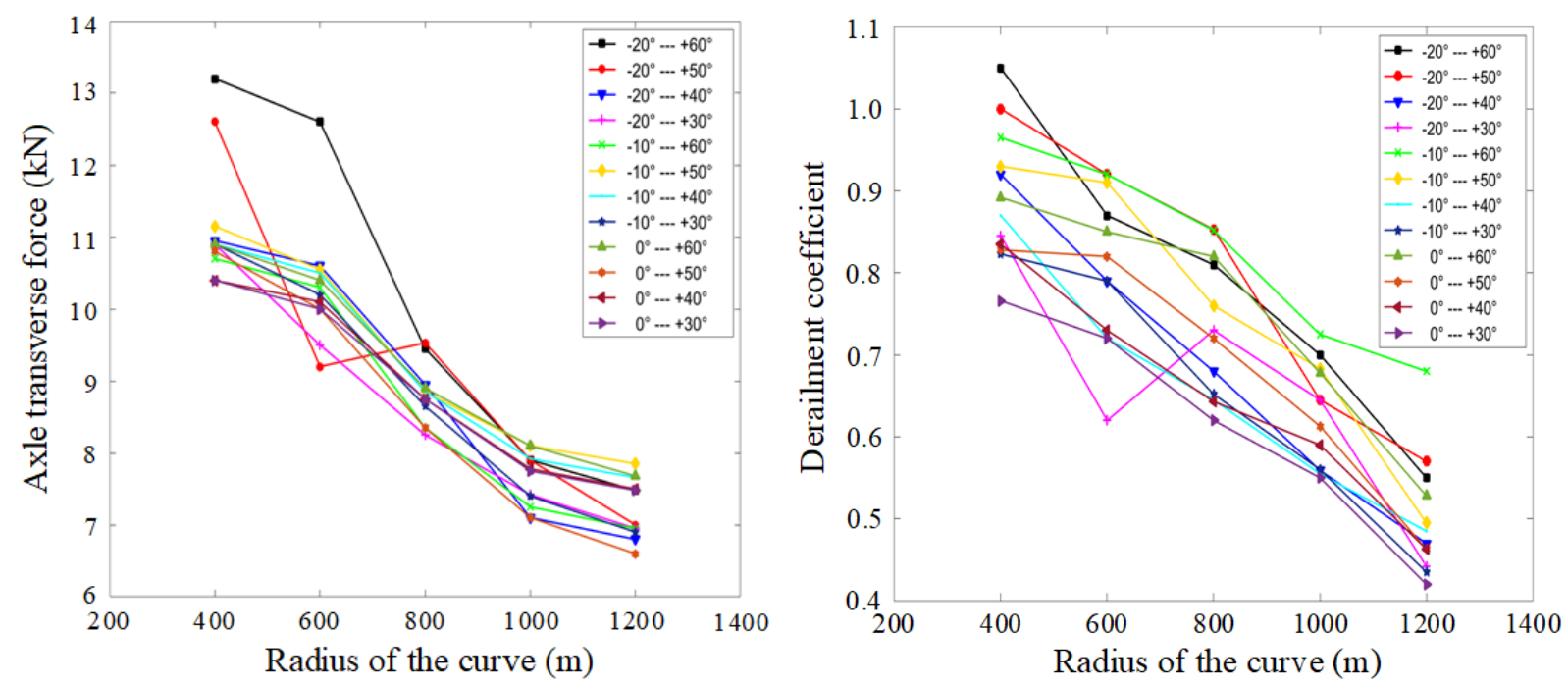

d)

Figure 11: Dynamic simulation results of the whole rail profile grinding for the curved track.

\section{CONCLUSION}

To compensate for the limitations in practical application and some functional deficiencies of the existing rail grinding technologies, a novel rail grinding device based on belt grinding technology with a closed belt structure was proposed in this paper. According to the features of the rail profile, regularity of corrugation and the relevant China National Standard (CNS), the novel rail grinding device is designed to have four grinding units, and is capable to eliminate the corrugation for the rail profile under the working speed from $12 \mathrm{~km} / \mathrm{h}$ to 32 $\mathrm{km} / \mathrm{h}$. The corresponding dynamic analysis was carried out by SIMPACK software to investigate the working performance of the designed device. The results show that the lateral vibration acceleration and the vertical vibration acceleration increase with the growth of the working speed and the radius of the curvature no matter for straight line or curved track. The derailment coefficient and the lateral force of the axle ascent with the increase of the working speed and the radius of the curvature for straight line, while an opposite trend can be found for curved track. It can be seen that the designed rail grinding device basically satisfies the requirements and constraints of rail vehicles. 


\section{ACKNOWLEDGEMENT}

This work was supported by the Fundamental Research Funds for the Central Universities (Grant No. 2019JBM050). The authors thank Prof. Jianyong Li for paper preparation and the anonymous reviewers for their helpful comments and suggestions.

\section{REFERENCES}

[1] Liu, Y.; Li, J.; Cai, Y.; Nie, M. (2014). Current state and development trend of rail grinding technology, China Railway Science, Vol. 35, No. 4, 29-37, doi:10.3969/j.issn.1001$\underline{4632.2014 .04 .05}$

[2] Fan, W.; Liu, Y.; Li, J. (2018). Development status and prospect of rail grinding technology for high speed railway, Journal of Mechanical Engineering, Vol. 54, No. 22, 184-193, doi:10.3901/JME.2018.22.184

[3] Steenbergen, M. (2016). Rolling contact fatigue in relation to rail grinding, Wear, Vol. 356-357, 110-121, doi:10.1016/j.wear.2016.03.015

[4] Real, J. I.; Zamorano, C.; Velarte, J. L.; Blanco, A. E. (2015). Development of a vehicle-track interaction model to predict the vibratory benefits of rail grinding in the time domain, Journal of Modern Transportation, Vol. 23, No. 3, 189-201, doi:10.1007/s4053-015-0078-y

[5] Zarembski, A. M. (2008). Grinding as part of rail management strategy, Railway Track and Structures, Vol. 104, No. 6, 55-58

[6] Zarembski, A. M. (2012). High-speed rail grinding and metal removal, Railway Track and Structures, Vol. 108, No. 6, 44-46

[7] Cuervo, P. A.; Santa, J. F.; Toro, A. (2015). Correlations between wear mechanisms and rail grinding operations in a commercial railroad, Tribology International, Vol. 82, Part B, 265-273, doi:10.1016/j.triboint.2014.06.025

[8] Gu, K. K.; Lin, Q.; Wang, W. J.; Wang, H. Y.; Guo, J.; Liu, Q. Y.; Zhu, M. H. (2015). Analysis on the effects of rotational speed of grinding stone on removal behavior of rail material, Wear, Vol. 342-343, 52-59, doi:10.1016/j.wear.2015.08.008

[9] Zhi, S.; Li, J.; Zarembski, A. M. (2015). Grinding motor energy saving method based on material removal model in rail grinding processes, International Journal of Precision Engineering and Manufacturing-Green Technology, Vol. 2, No. 1, 21-30, doi:10.1007/s40684-015-0003-1

[10] Santa, J. F.; Toro, A.; Lewis, R. (2016). Correlations between rail wear rates and operating conditions in a commercial railroad, Tribology International, Vol. 95, 5-12, doi:10.1016/j.triboint.2015.11.003

[11] Zhang, Z. Y.; Shang, W.; Ding, H. H.; Guo, J.; Wang, H. Y.; Liu, Q. Y.; Wang, W. J. (2016). Thermal model and temperature field in rail grinding process based on a moving heat source, Applied Thermal Engineering, Vol. 106, 855-864, doi:10.1016/j.applthermaleng.2016.06.071

[12] Singleton, R.; Marshall, M. B.; Lewis, R.; Evans, G. (2014). Rail grinding for the $21^{\text {st }}$ century taking a lead from the aerospace industry, Proceedings of the Institution of Mechanical Engineers, Part F: Journal of Rail and Rapid Transit, Vol. 229, No. 5, 457-465, doi:10.1177/ $\underline{0954409714527929}$

[13] Uhlmann, E.; Lypovka, P.; Hochschild, L.; Schröer, N. (2016). Influence of rail grinding process parameters on rail surface roughness and surface layer hardness, Wear, Vol. 366-367, 287-293, doi:10.1016/j.wear.2016.03.023

[14] Linsinger. Linsinger Rail Milling Train SF03-FFS, from http://www.linsinger.com/portfolio/sfo3ffs/?lang=en, accessed on 03-07-2018

[15] Vossloh. Rail and Turnouts Maintenance, from https://www.vossloh.com/en/products-andsolutions/products-at-a-glance/rail-turnouts.maintenance/, accessed on 03-06-2018

[16] He, Z.; Li, J.; Liu. Y.; Nie, M.; Fan, W. (2017). Investigating the effects of contact pressure on rail material abrasive belt grinding performance, The International Journal of Advanced Manufacturing Technology, Vol. 93, No. 1-4, 779-786, doi:10.1007/s00170-017-0498-4

[17] Fan, W.; Liu, Y.; Song, X.; Cheng, J.; Li, J. (2018). Influencing mechanism of rubber wheel on contact pressure and metal removal in corrugated rail grinding by abrasive belt, Journal of 
Manufacturing Science and Engineering, Vol. 140, No. 12, Paper 12451, 8 pages, doi: $10.1115 / 1.4041243$

[18] Fan, W.; Liu, Y.; Wang, W.; Li, J.; Wang, R. (2018). Research on modeling method of material removal for rail grinding by abrasive belt based on elastic Hertzian contact, Journal of Mechanical Engineering, Vol. 54, No. 15, 191-198, doi:10.3901/JME.2018.15.191

[19] Magel, E. E.; Kalousek, J. (2002). The application of contact mechanics to rail profile design and rail grinding, Wear, Vol. 253, No. 1-2, 308-316, doi:10.1016/S0043-1648(02)00123-0

[20] Hartsough, C. M.; Palese, J. W.; Schmitzer, G.; Espindola, J. C.; Viana, T. G. (2016). Optimized rail grinding through dynamic positioning and powering of grinding motors, Proceedings of the 2016 ASME Joint Rail Conference, Paper JRC2016-5718, 10 pages, doi:10.1115/JCR2016-5718

[21] China Railway Corporation (2015). Assembly technical conditions of rail grinding device: TJ/GW131-2015I, China Railway Industry Standard

[22] Li, L. (2018). Mechanism design and motion planning of parallel-chain nonholonomic manipulator, International Journal of Simulation Modelling, Vol. 17, No. 2, 327-336, doi:10.2507/IJSIMM17(2)CO7

[23] National Quality Technical Supervise Department (1998). Dynamic performance evaluation and test method for particular class vehicles and tracked machine GB/T 17426-1998, China National Standard 